\title{
Antioxidant Activity of Lactobacillus plantarum DY-1 Fermented Wheat Germ Extract and Its Influence on Lipid Oxidation and Texture Properties of Emulsified Sausages
}

\author{
Juan Wu, ${ }^{1,2}$ Yu Cheng $\mathbb{D}^{1,2}$ and Ying Dong ${ }^{1}$ \\ ${ }^{1}$ School of Food and Biological Engineering, Jiangsu University, 301 Xuefu Road, Zhenjiang, Jiangsu 212013, China \\ ${ }^{2}$ Institute of Food Physical Processing, Jiangsu University, 301 Xuefu Road, Zhenjiang, Jiangsu 212013, China \\ Correspondence should be addressed to Yu Cheng; chengyu@ujs.edu.cn
}

Received 24 June 2020; Revised 7 July 2020; Accepted 3 August 2020; Published 18 August 2020

Academic Editor: Yiren Yue

Copyright (c) 2020 Juan Wu et al. This is an open access article distributed under the Creative Commons Attribution License, which permits unrestricted use, distribution, and reproduction in any medium, provided the original work is properly cited.

\begin{abstract}
The nutrient compositions and in vitro antioxidant activities of water-soluble extract from Lactobacillus plantarum DY-1 fermented wheat germ and its effect on the lipid oxidation and texture properties of emulsified sausages were investigated. The optimal hydroxyl radical scavenging capacity of $72.8 \pm 2.9 \%$ was demonstrated for fermented wheat germ extract (FWGE) by terms of the fermentation conditions as follows: fermentation time of $26 \mathrm{~h}$, fermentation temperature of $35^{\circ} \mathrm{C}$, initial $\mathrm{pH}$ of 3.0 , solid to liquid ratio of $1 / 10$, and inoculum amount of $0.48 \mathrm{~g}$. The enhancement in FWGE content could improve the oxidation stability of emulsified sausages by retarding the formation of thiobarbituric acid-reactive substances (TBARSs) during 7 days of storage at $4^{\circ} \mathrm{C}$. However, a higher FWGE content $(2.14 \%)$ resulted in $78 \%$ of increase in cooking loss $(p<0.05)$ and $41.4 \%$ of decrease in hardness $(p<0.05)$ of emulsified sausages. It was suggested that the biotransformation of wheat germ with lactic acid bacteria could improve its nutritional quality and functional properties.
\end{abstract}

\section{Introduction}

Although synthetic antioxidants such as butylated hydroxytoluene (BHT), butylated hydroxyanisole (BHA), and tert-butylhydroquinone (TBHQ) have widely been used in retarding lipid oxidation, their safety has been questioned due to toxicity and possible carcinogenicity [1].Thus, development of natural antioxidants has been of interest. Peptides, flavonoids, and other phenolic compounds from natural sources have been carried out to be potential natural antioxidants in food industry [2-6]. As cereals are good source of protein and phenolic compounds, utilizing the ingredients in cereals as the natural antioxidants was a concern for many researchers [7-9]. However, the compounds with potential antioxidant capacities in cereals are usually bounded into the matrix of cereals [10]. This hinders their antioxidant capacities. To improve the antioxidant properties of cereals, microbial bioprocessing was used to release antioxidant peptides and phenolic compounds from cereals [11-13].

Wheat germ, which is the by-product of flour milling industry, contains a lot of components with a high nutritional value. After extracting the wheat germ oil, the defatted wheat germ still contains components including protein and phenolic compounds. Both peptides released from wheat germ protein by commercial enzyme [14] and phenolic compounds [15] extracted from wheat germ have showed antioxidant activities. However, these studies concerned on only peptides or phenolic compounds. Little has been done to take use of both protein and phenolic compounds. And combining the antioxidant peptides and phenolic compounds has shown to improve the oxidation stability of food emulsions [16].

Microbial biotransformation using Bacillus subtilis or Aspergillus oryzae has been turn out to be able to convert the protein to peptides [17] and release phenolic compounds [18] from wheat germ. The antioxidant activities of wheat 
germ fermentation were facilitated by fermentation. And the fermented wheat germ was able to improve the quality of bread [19]. However, few studies have been done on using lactic acid bacteria fermentation to improve the antioxidant activities of wheat germ. Also, using the fermented products as a functional food ingredient to retard lipid oxidation of food is rare.

The objective of present study was to optimize the antioxidant properties of water-soluble extract from fermented defatted wheat germ prepared with the lactic acid bacteria of Lactobacillus plantarum DY-1 and assess its role on lipid oxidation of emulsified sausages.

\section{Materials and Methods}

2.1. Materials. Lactobacillus plantarum DY-1 direct-vatstarter (DVS) with a cell density of $10^{10} \mathrm{cfu} / \mathrm{g}$ was screened and prepared by our group [20]. Defatted wheat germ power was purchased from Mantianxue Co. (Henan, China). Ferrozine was purchased from Sigma Chemical Co. (St. Louis, USA). Fresh pork and pork fat were purchased from local supermarket. All other reagents were of analytical grade and purchased from Sinopharm Chemical Reagent Co. Ltd (Shanghai, China).

2.2. Experiment Design and Fermentation. Defatted wheat germs were dispersed into $100 \mathrm{~mL}$ of citrate buffer in $250 \mathrm{~mL}$ conical flasks, followed by mixing with Lactobacillus plantarum DY-1 DVS. After sealing with gauze, the defatted wheat germs were fermented in the shaker at the speed of $120 \mathrm{r} / \mathrm{min}$. Uniform experimental design [21] with five factors and 12 of runs was used to analyze the fermentation parameters by terms of chemical compositions and antioxidant activities, as shown in Table 1 . The fermentation parameters including fermentation time $\left(X_{1}\right)$, temperature $\left(X_{2}\right), \mathrm{pH}\left(X_{3}\right)$, ratio of solid to liquid $\left(X_{4}\right)$, and inoculation amount $\left(X_{5}\right)$ were evaluated. The experiments were carried out in random order. And the response functions including soluble protein content $\left(Y_{1}\right)$, total phenolic content $\left(Y_{2}\right)$, total sugar content $\left(Y_{3}\right)$, reducing sugar content $\left(Y_{4}\right), \mathrm{Fe}^{2+}$ chelating activity $\left(Y_{5}\right)$, hydroxyl free radical scavenging capacity $\left(Y_{6}\right)$, and superoxide anion radical scavenging capacity $\left(Y_{7}\right)$ of fermented wheat germ extract (FWGE) were assessed.

The relationship between independent variables and responses was expressed with second-order polynomial regression model as follows:

$$
Y=\beta_{0}=\sum_{i-1}^{m} \beta_{i} X_{i}+\sum_{i=1}^{m} \beta_{i i} X_{i}^{2}+\sum_{i<j} \beta_{i j} X_{i} X_{j}+e,
$$

where $Y$ is the response variable; $\beta_{0}, \beta_{i}, \beta_{i i}$, and $\beta_{i j}$ are the regression coefficients; and $X_{i}$ and $X_{j}$ are the independent variables.

\subsection{Preparation of Fermented Wheat Germ Extract (FWGE).} Fermented wheat germs were centrifuged at $8000 \mathrm{~g}$ for 15 min by Avanti J-26S (Beckman Coulter, Inc., CA, USA).
The supernatants were collected and freeze-dried for $48 \mathrm{~h}$. The lyophilized water-soluble fermented wheat germ extracts were stored at $-20^{\circ} \mathrm{C}$ before further analysis.

\subsection{Radical Scavenging Activities of FWGE}

2.4.1. Superoxide Anion Radical Scavenging Activity. The superoxide anion scavenging activity of FWGE solutions was determined by the method of Tang et al. [22] and the methods description partly reproduces their wording. The mixture of $1 \mathrm{~mL}$ FWGE $(2 \mathrm{mg} / \mathrm{mL})$ and $1.8 \mathrm{~mL}$ of Tris- $\mathrm{HCl}$ buffer $(50 \mathrm{mM}, \mathrm{pH} 8.2)$ was incubated at $25^{\circ} \mathrm{C}$ for $10 \mathrm{~min}$, followed by adding $0.1 \mathrm{~mL}$ of pyrogallol solution $(10 \mathrm{mM})$. The absorbance of solution was recorded every $15 \mathrm{~s}$ in $3 \mathrm{~min}$ at the wavelength of $320 \mathrm{~nm}$. The slope of the linear regression equation according to the absorbance and time was used to indicate the oxidation rate of pyrogallol $\left(V_{\mathrm{s}}\right)$. Deionized water was used as the control to determine the autoxidation rate of pyrogallol $\left(\mathrm{V}_{0}\right)$. The superoxide anion radical scavenging activity was expressed as $\left[\left(\mathrm{V}_{0}-V_{\mathrm{s}}\right) / \mathrm{V}_{0}\right] \times 100 \%$.

2.4.2. Hydroxyl Radical Scavenging Activity. Hydroxyl radical scavenging activity of FWGE solutions was measured according to the method of Li et al. [23] and the methods description partly reproduces their wording. One milliliter of $200 \mathrm{mM}$ phosphate buffer ( $\mathrm{pH} 7.4$ ) was mixed with $0.5 \mathrm{~mL}$ of 1,10-phenanthroline $(0.75 \mathrm{mM})$ and $0.5 \mathrm{~mL}$ of $\mathrm{FeSO}_{4}$ $(0.75 \mathrm{mM})$, followed by adding $0.5 \mathrm{~mL}$ of $\mathrm{H}_{2} \mathrm{O}_{2}(0.01 \%)$ and $0.5 \mathrm{~mL}$ of FWGE $(20 \mathrm{mg} / \mathrm{mL})$. After holding at $37^{\circ} \mathrm{C}$ for $60 \mathrm{~min}$, the absorbance of the mixture was recorded at $536 \mathrm{~nm}$. The hydroxyl radical scavenging activity was expressed as $\left[\left(A_{\mathrm{s}}-A_{1}\right) /\left(A_{0}-A_{1}\right)\right] \times 100 \%$, where As is the absorbance value of the samples; $A_{1}$ is the absorbance value of control solution containing 1,10-phenanthroline, $\mathrm{FeSO}_{4}$, and $\mathrm{H}_{2} \mathrm{O}_{2}$; and $A_{0}$ is the absorbance value of blank solution containing 1,10-phenanthroline and $\mathrm{FeSO}_{4}$.

2.5. Fe2+ Chelating Activity. Ferrous metal ion chelating activity of FWGE solutions was determined according to the method of Cheng et al. [24] and the methods description partly reproduces their wording. Two milliliters of ferrozine $(500 \mu \mathrm{M})$ was mixed with $1 \mathrm{~mL}$ of $\mathrm{FeCl}_{2}(20 \mu \mathrm{M})$, followed by adding $0.5 \mathrm{~mL}$ of FWGE solutions $(8 \mathrm{mg} / \mathrm{mL})$. The absorbance of the mixture was recorded at $562 \mathrm{~nm}\left(A_{\mathrm{s}}\right)$ after $10 \mathrm{~min}$ incubation. Deionized water was used as the control to determine the absorbance of the mixture $\left(A_{0}\right)$. The $\mathrm{Fe}^{2+}$ chelating activity was calculated as $\left[\left(A_{0}-A_{\mathrm{s}}\right) / A_{0}\right] \times 100 \%$.

2.6. Chemical Analysis of FWGE. The content of total phenols was evaluated using in FWGE Folin-Ciocalteu method, as described by Zhang et al. [20]. The content of soluble protein, total sugar, and reducing sugar was determined by the biuret method [25], anthrone-sulfuric acid colorimetric method, and dinitrosalicylic acid method [26], respectively. 
TABLE 1: Uniform design for lactic acid bacteria fermentation of wheat germ.

\begin{tabular}{|c|c|c|c|c|c|c|c|c|c|c|c|c|}
\hline \multirow{2}{*}{ Run } & \multicolumn{5}{|c|}{ Independent variables (coded and uncoded) } & \multicolumn{7}{|c|}{ Responses } \\
\hline & $X_{1}$ & $X_{2}$ & $X_{3}$ & $X_{4}$ & $X_{5}$ & $Y_{1}$ & $Y_{2}$ & $Y_{3}$ & $Y_{4}$ & $Y_{5}$ & $Y_{6}$ & $Y_{7}$ \\
\hline 1 & (1) 6 & (3) 25 & (4) 3.5 & (9) $1 / 8$ & (12) 0.6 & 364.7 & 5.8 & 403.5 & 162.7 & 18.9 & 16.4 & 19.1 \\
\hline 2 & (2) 6 & (6) 30 & (8) 4.5 & (5) $1 / 6$ & (11) 0.6 & 275.0 & 6.4 & 583.7 & 115.5 & 7.5 & 53.4 & 10.4 \\
\hline 3 & (3) 12 & (9) 40 & (12) 5.5 & (1) $1 / 2$ & 0.5 & 304.9 & 6.5 & 404.3 & 190.0 & 12.1 & 33.5 & 9.0 \\
\hline 4 & (4) 12 & (12) 45 & (3) 3.5 & (10) $1 / 8$ & (9) 0.5 & 265.6 & 9.0 & 604.6 & 126.5 & 2.3 & 27.8 & 2.0 \\
\hline 5 & (5) 18 & (2) 20 & (7) 4.5 & (6) $1 / 6$ & (8) 0.4 & 273.3 & 7.4 & 587.7 & 137.5 & 14.7 & 24.9 & 6.1 \\
\hline 6 & (6) 18 & (5) 30 & (11) 5.5 & (2) $1 / 2$ & (7) 0.4 & 333.5 & 6.9 & 480.7 & 158.9 & 5.5 & 32.1 & 5.2 \\
\hline 7 & (7) 24 & (8) 35 & (2) 3.0 & (11) $1 / 10$ & (6) 0.3 & 345.9 & 9.7 & 364.9 & 157.3 & 1.4 & 68.9 & 28.6 \\
\hline 8 & (8) 24 & (11) 45 & (6) 4.0 & (7) $1 / 7$ & (5) 0.3 & 375.1 & 8.0 & 331.1 & 152.7 & 25.9 & 26.8 & 13.2 \\
\hline 9 & (9) 30 & (1) 20 & 5.0 & (3) $1 / 4$ & (4) 0.2 & 244.1 & 8.9 & 526.6 & 151.8 & 23.9 & 65.0 & 10.7 \\
\hline 10 & (10) 30 & (4) 25 & (1) 3.0 & (12) $1 / 10$ & (3) 0.2 & 347.9 & 10.5 & 615.1 & 55.7 & 0.2 & 58.7 & 17.6 \\
\hline 11 & 36 & (7) 35 & (5) 4.0 & (8) $1 / 7$ & (2) 0.1 & 224.9 & 8.1 & 611.9 & 123.9 & 7.0 & 12.3 & 1.6 \\
\hline 12 & (12) 36 & (10) 40 & (9) 5.0 & (4) $1 / 4$ & (1) 0.1 & 291.1 & 9.0 & 582.1 & 54.0 & 2.2 & 17.6 & 6.0 \\
\hline Control & \multicolumn{5}{|c|}{ Unfermented wheat germ } & 154.6 & 3.4 & 845.0 & 36.0 & 64.4 & 39.5 & -29.6 \\
\hline
\end{tabular}

$X 1$ : fermentation time $(\mathrm{h}) ; X_{2}$ : fermentation temperature $\left({ }^{\circ} \mathrm{C}\right) ; X_{3}$ : initial $\mathrm{pH} ; X_{4}$ : solid/liquid ratio $(\mathrm{g} / \mathrm{mL}) ; X_{5}$ : inoculum amount $(\mathrm{g})$; $Y_{1}$ : soluble protein content $(\mathrm{mg} / \mathrm{g}) ; Y_{2}$ : total phenolic content $(\mathrm{mg} / \mathrm{g}) ; Y_{3}$ : total sugar content $(\mathrm{mg} / \mathrm{g}) ; Y_{4}:$ reducing sugar content $(\mathrm{mg} / \mathrm{g}) ; Y_{5}: \mathrm{Fe}^{2+}$ chelating activity $(\%) ; Y_{6}$ : hydroxyl radical scavenging capacity (\%); $Y_{7}$ : superoxide anion scavenging capacity (\%).

2.7. Preparation of Emulsified Sausages. The emulsified sausages were prepared as described by Nieto et al. [27] and the methods description partly reproduced their wording. Lean and pork fat were minced through $5 \mathrm{~mm}$ and $3 \mathrm{~mm}$ plate, respectively, using a meat grinder. The grounded lean and fat were mixed with crushed ice, FWGE, chilled water $\left(2^{\circ} \mathrm{C}\right)$, and salt according to the formula in Table 2 . The fat in emulsified sausages was replaced with $0,2 \%, 5 \%, 7 \%$, and $10 \%$ of FWGE. After being chopped for $5 \mathrm{~min}$ to form meat emulsions, the mixture was stuffed into manufactured collagen casings with the diameter of $29 \mathrm{~mm}$ by a stuffer (MGJ-090, Demas Network Technology Co., Ltd, Foshan, China). The samples were then tied and cut into sausages with the length of $10 \mathrm{~cm}$ by hand. The sausages were heated in a steamer until their central temperature was kept at $80 \pm 2^{\circ} \mathrm{C}$ for $20 \mathrm{~min}$. The central temperature of sausages was measured with thermocouple thermometer. The cooked sausages were cooled with cold water, sealed in polyethylene bags using vacuum packing, and maintained at $4^{\circ} \mathrm{C}$ for 7 days to estimate the oxidation stability.

2.8. Cooking Loss. The emulsified sausages were weighed before the heating process and after the cooling process. The cooking loss was expressed as the weight loss between initial $\left(W_{0}\right)$ and final $\left(W_{\mathrm{f}}\right)$ weight of the sausages and calculated as $\left[\left(W_{0}-W_{\mathrm{f}}\right) / \mathrm{W}_{0}\right] \times 100 \%$.

2.9. Thiobarbituric Acid-Reactive Substances (TBARSs). The method of Nieto et al. [27] was used to assess the lipid oxidation of sausages and the methods description partly reproduced their wording. TBARS value was determined by the following equation: TBARS $(\mathrm{mg} / \mathrm{kg})=\left(A_{532} / W_{s}\right) \times 9.48$, where $A_{532}$ was the absorbance of the red TBA reaction product at $532 \mathrm{~nm}, W_{\mathrm{s}}$ was the sausage sample weight $(\mathrm{g})$, and 9.48 was a constant derived from the dilution factor and the molar extinction coefficient $\left(1.52 \times 10^{3} \mathrm{M}^{-1} \cdot \mathrm{cm}^{-1}\right)$ of the red TBA reaction product.
TABLe 2: Formulation of emulsified sausages.

\begin{tabular}{lccccc}
\hline \multirow{2}{*}{ Formula } & \multicolumn{5}{c}{ Treatment (fat replacement ratio with FWGE) } \\
& $0 \%$ & $2 \%$ & $5 \%$ & $7 \%$ & $10 \%$ \\
\hline Fat $(\mathrm{g})$ & 107 & 104.86 & 101.65 & 99.51 & 96.3 \\
Lean $(\mathrm{g})$ & 249.5 & 249.5 & 249.5 & 249.5 & 249.5 \\
FWGE $(\mathrm{g})$ & 0 & 2.14 & 5.35 & 7.49 & 10.7 \\
Water $(\mathrm{g})$ & 86 & 86 & 86 & 86 & 86 \\
Ice $(\mathrm{g})$ & 50 & 50 & 50 & 50 & 50 \\
NaCl $(\mathrm{g})$ & 7.5 & 7.5 & 7.5 & 7.5 & 7.5 \\
Total $(\mathrm{g})$ & 500 & 500 & 500 & 500 & 500 \\
\hline
\end{tabular}

2.10. Texture Profile Analysis (TPA). TPA was performed at room temperature using a texture analyzer (TA-XT Plus, Stable Micro Systems Ltd., Surrey, UK) with the compression distance of $10.0 \mathrm{~mm}$ using P50 probe. The pretest speed, test speed, and posttest speed were $2.0,1.0$, and $1.0 \mathrm{~mm} / \mathrm{s}$, respectively, as described by Cheng et al. [28]. All sausage samples were stripped of the casings and cut into cylinders with the length of $20 \mathrm{~mm}$ before analysis.

2.11. Statistical Analyses. All assays were done in triplicate. Two different batches of raw materials were used to prepare emulsified sausages at different days. The data were analyzed using DPS statistical software (V9.5, Hangzhou, China) [29] in one-way analysis of variance (ANOVA). The differences between means were compared with the LSD test, and significant difference was considered when $p<0.05$. Uniform design and its regression model assays were also carried out with DPS statistical software.

\section{Results and Discussion}

3.1. Composition Analysis of FWGE. The chemical compositions of FWGE at different fermentation conditions by terms of uniform design are listed in Table 1. Fermentation with Lactobacillus plantarum DY-1 increased the content of soluble protein, total phenolic, and reducing sugar while 
resulted in decrease in the content of total sugar. These results can be explained by the fact that levels of bioactive compounds can be modified by the biotransformation activity of microbes. Also, fermentation might result in breakdown of cell walls in wheat germ cells and release their endogenous enzymes. Enzymes such as amylases, xylanases, and proteases derived from the microbes and cereals might contribute to the conversion of compositions in cell of cereals [30]. The metabolism of Lactobacillus plantarum DY-1 could lead to the liberation and/or synthesis of various bioactive compounds. It was demonstrated that fermentation has a positive influence on total phenolic content and antioxidant activity of cereals $[12,14]$. And the degree of influence depended on microorganism species [31]. Our result was consisted with previous research of Zhang et al. [20] that total phenolic content was enhanced by fermentation with Lactobacillus plantarum DY-1.

3.2. Antioxidant Activities of FWGE. The results of antioxidant activities (Table 1) showed that fermentation improved the superoxide anion radical scavenging activity of wheat germ water extracts while weakened their $\mathrm{Fe}^{2+}$ chelating activity. And the hydroxyl radical scavenging activity could be enhanced at the selected fermentation conditions.

The Pearson correlation was used to display the relation between chemical compositions and antioxidant activities of FWGE. As shown in Table 3, soluble protein content of FWGE was in significant positive correlation with its superoxide anion radical scavenging activity. Endogenous proteases of wheat germ and proteases from DY-1 could hydrolyze the wheat germ protein into protein hydrolysate. This would result in improvement of the solubility of wheat germ protein. It has been showed by many research studies that protein hydrolysates exhibit higher antioxidant capacities than their original proteins. However, it was strange that the total phenolic content of FWGE was not significantly correlative with their antioxidant capacities. It suggested that the wheat germ protein hydrolysate might contribute more to their antioxidant activities. It was interesting that the soluble protein content of FWGE showed significant negative correlation with its total sugar content. It seemed that wheat germ protein was bounded with polysaccharides in wheat germ. Fermentation released the wheat germ protein bounded from the matrix of polysaccharides.

3.3. Optimizing Fermentation Conditions. To optimize the fermentation condition for better antioxidant activities, quadratic polynomial regression equation was used to express the relationship between fermentation conditions and antioxidant activities of FWGE. The details of regression equations are shown in Table 4. Since only the model for regression equation of hydroxyl radical scavenging activity was significant, it was used for further analysis. The Durbin-Watson value of 1.96 for that model was close to 2 . And the $R^{2}$ of the model was 0.9997 . All the results indicated that regression equation of hydroxyl radical scavenging activity
TABle 3: Pearson correlation of chemical compositions and antioxidant capacities of FWGE.

\begin{tabular}{cccccccc}
\hline & $y 1$ & $y 2$ & $y 3$ & $y 4$ & $y 5$ & $y 6$ & $y 7$ \\
\hline$y 1$ & 1 & -0.044 & $-0.693^{*}$ & 0.042 & 0.099 & 0.088 & $0.669^{*}$ \\
$y 2$ & & 1 & 0.277 & -0.536 & -0.414 & 0.441 & 0.213 \\
$y 3$ & & & 1 & $-0.662^{*}$ & -0.465 & -0.081 & $-0.582^{*}$ \\
$y 4$ & & & & 1 & 0.495 & 0.075 & 0.055 \\
$y 5$ & & & & 1 & -0.118 & 0.031 \\
$y 6$ & & & & & 1 & $0.585^{*}$
\end{tabular}

$y 7$

1

*Significant at $p<0.05 . Y_{1}$ : soluble protein content $(\mathrm{mg} / \mathrm{g}) ; Y_{2}$ : total phenolic content $(\mathrm{mg} / \mathrm{g}) ; Y_{3}$ : total sugar content $(\mathrm{mg} / \mathrm{g}) ; Y_{4}$ : reducing sugar content $(\mathrm{mg} / \mathrm{g}) ; Y_{5}: \mathrm{Fe}^{2+}$ chelating activity (\%); $Y_{6}: \cdot \mathrm{OH}$ scavenging capacity (\%); $Y_{7}$ : $\mathrm{O}_{2}^{-}$scavenging capacity (\%).

TABle 4: Significance of regression coefficients and regression equations for antioxidant activities of lactic acid bacteria fermented wheat germ extract.

\begin{tabular}{lccc}
\hline Coefficients & $Y_{5}$ & $Y_{6}$ & $Y_{7}$ \\
\hline$\beta_{0}$ & -1893.5 & -1628.8 & 73.5 \\
$\beta_{2}$ & $22.4^{*}$ & & \\
$\beta_{3}$ & & $3324.6^{*}$ & $-76.4^{*}$ \\
$\beta_{4}$ & & $-71455.4^{*}$ & \\
$\beta_{5}$ & -66.1 & & $171.4^{*}$ \\
$\beta_{12}$ & & & $0.112^{*}$ \\
$\beta_{14}$ & $654.5^{*}$ & 3.0 & \\
$\beta_{15}$ & & $-5.39^{*}$ & \\
$\beta_{23}$ & & $-1.34^{*}$ & -0.138 \\
$\beta_{24}$ & $26.4^{*}$ & & $-9.78^{*}$ \\
$\beta_{25}$ & & $4.64^{*}$ & \\
$\beta_{34}$ & $-4257.8^{*}$ & $17215.0^{*}$ & $346.6^{*}$ \\
$\beta_{35}$ & $378.8^{*}$ & & $-28.8^{*}$ \\
$\beta_{45}$ & $37154.6^{*}$ & & $1389.7^{*}$ \\
$\beta_{2}{ }^{2}$ & $-0.43^{*}$ & $0.058^{*}$ & \\
$\beta_{3}{ }^{2}$ & & $-656.8^{*}$ & \\
$\beta_{4}{ }^{2}$ & & & \\
$\beta_{5}{ }^{2}$ & $-3782.8^{*}$ & $-32971.6^{*}$ & $-3083.8^{*}$ \\
$R^{2}$ of model & $-1585.6^{*}$ & & -34.5 \\
Adjusted $R^{2}$ & 0.998 & 0.9997 & 0.997 \\
Significant of model & 0.976 & 0.997 & 0.973 \\
Durbin-Watson & 0.114 & 0.040 & 0.121 \\
\hline
\end{tabular}

${ }^{*}$ Significant at $p<0.05 . Y_{5}: \mathrm{Fe}^{2+}$ chelating activity (\%); $Y_{6}: \cdot \mathrm{OH}$ scavenging capacity (\%); $Y_{7}: \mathrm{O}_{2}^{-}$scavenging capacity (\%).

was able to well predict the change in hydroxyl radical scavenging activity by terms of fermentation parameters. The predicted model could be described as follows:

$$
\begin{aligned}
Y_{1}= & -1628.8+3324.6 X_{3}-71455.4 X_{4}++3.0 X_{1} * X_{4} \\
& -5.4 X_{1} * X_{5}-1.34 X_{2} * X_{3}+4.6 X_{2} * X_{5}+17215.0 X_{3} \\
& * X_{4}+0.058 X_{2} * X_{2}-656.8 X_{3} * X_{3}-32971.6 X_{4} * X_{4} .
\end{aligned}
$$

Based on the regression model, an optimum condition of fermentation was demonstrated as follows: fermentation time of $26 \mathrm{~h}$, fermentation temperature of $35^{\circ} \mathrm{C}$, initial $\mathrm{pH}$ of 3.0, solid to liquid ratio of $1 / 10$, and inoculum amount of $0.48 \mathrm{~g}$. The verification experiment at the above conditions 


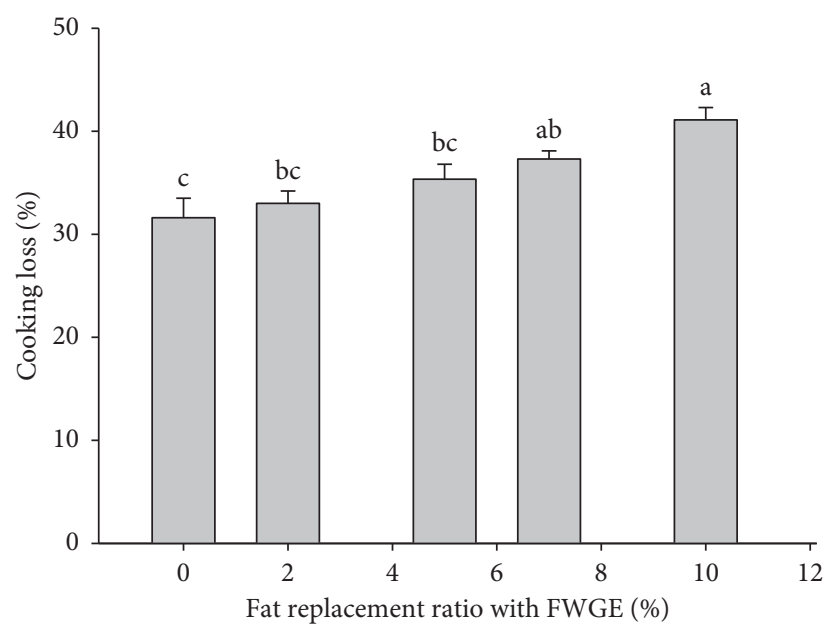

FIgure 1: Cooking loss of emulsified sausages with different ratios of fat replacement using FWGE.

TABLE 5: Texture properties analysis of emulsified sausages with different concentrations of FWGE.

\begin{tabular}{lccccc}
\hline FWGE (\%) & Hardness $(\mathrm{g})$ & Resilience $(\%)$ & Springiness $(\%)$ & Cohesiveness $^{\text {Chewiness }}$ \\
\hline 0 & $2098.1 \pm 161.0^{\mathrm{a}}$ & $19.9 \pm 2.7^{\mathrm{a}}$ & $73.4 \pm 2.3^{\mathrm{a}}$ & $0.47 \pm 0.03^{\mathrm{a}}$ & $706.0 \pm 62.4^{\mathrm{a}}$ \\
0.43 & $2514.5 \pm 341.3^{\mathrm{a}}$ & $17.7 \pm 5.6^{\mathrm{a}}$ & $74.2 \pm 2.2^{\mathrm{a}}$ & $0.44 \pm 0.08^{\mathrm{ab}}$ & $828.0 \pm 237.8^{\mathrm{a}}$ \\
1.07 & $2049.0 \pm 259.5^{\mathrm{a}}$ & $14.1 \pm 2.1^{\mathrm{a}}$ & $70.4 \pm 0.9^{\mathrm{a}}$ & $0.38 \pm 0.03^{\mathrm{ab}}$ & $550.9 \pm 113.1^{\mathrm{a}}$ \\
1.50 & $1606.8 \pm 788.2^{\mathrm{ab}}$ & $12.4 \pm 4.6^{\mathrm{a}}$ & $68.5 \pm 1.5^{\mathrm{a}}$ & $0.34 \pm 0.08^{\mathrm{ab}}$ & $358.5 \pm 114.2^{\mathrm{a}}$ \\
2.14 & $1478.7 \pm 203.7^{\mathrm{b}}$ & $11.4 \pm 1.4^{\mathrm{a}}$ & $55.4 \pm 16.1^{\mathrm{a}}$ & $0.33 \pm 0.04^{\mathrm{b}}$ & $300.5 \pm 111.7^{\mathrm{a}}$ \\
\hline
\end{tabular}

All values are presented as mean \pm standard deviation of three replicates $(n=2) .{ }^{\mathrm{a}, \mathrm{b}}$ Means within a column with different superscript letters are significantly different $(p<0.05)$.

was carried out in two replicates. And the hydroxyl radical scavenging capacity and $\mathrm{Fe}^{2+}$ chelating capacity of FWGE were $72.8 \pm 2.9 \%$ and $20.5 \pm 3.6 \%$, respectively. The optimized hydroxyl radical scavenging capacity of FWGE was 1.84 times higher than the wheat germ water-soluble extract.

3.4. Effect of FWGE Content on Cooking Loss. The effect of the replacement of pork fat with FWGE on the cooking loss of the emulsified sausages is shown in Figure 1. The replacement of pork fat at the ratio lower than $5 \%$ did not change the cooking loss of the sausages $(p>0.05)$. However, increasing the replacement ratio of $7-10 \%$ would lead to enhancement in the cooking loss of sausages $(p<0.05)$. The cooking loss of the sausages with $10 \%$ of fat replacement was increased by 1.30 times.

\subsection{Effect of FWGE Content on Texture of Emulsified} Sausages. As shown in Table 5, addition of FWGE had little effect on the textural properties of emulsified sausages including hardness, resilience, springiness, cohesiveness, and chewiness. Increasing the content of FWGE seemed to reduce the hardness of emulsified sausages. When ten percent of fat was replaced with FWGE, the hardness and cohesiveness of the emulsified sausages were reduced by 41.2 and $42.4 \%$ $(p<0.05)$, respectively. The reason was that FWGE might hinder the formation of protein gel network of emulsified sausages and weakened the gel properties of them. Emulsified sausage is a model of emulsion filled myofibrillar protein gel. The hardness of emulsified sausage is usually influenced by the filler of oil droplet and the matrix of protein gel network. As FWGE was not able to form the viscoelastic particles, the replacement of oil with FWGE might reduce the viscoelastic property of the filler. This might result in the weak hardness of the sausages. The phenols in the FWGE might combine with myofibrillar protein and prevent its aggregation. This might lead to destruction in the formation of myofibrillar protein network. Also, the free amino acid released might have negative effect on the texture of protein gel $[32,33]$. Thus, the hardness and cohesiveness of the emulsified sausages might decrease.

3.6. Effect of FWGE Content on Lipid Oxidation of Emulsified Sausages. FWGE was able to retard lipid oxidation of emulsified due to its antioxidant activities. The emulsified sausages with FWGE demonstrated a higher oxidation stability than that without FWGE. The effect of the FWGE on retarding lipid oxidation of emulsified sausages during 7 days of storage at $4^{\circ} \mathrm{C}$ is shown in Figure 2. At 0 days of storage, the formation of TBARS was inhibited by 36.4 and $78.3 \%$ at the FWGE content of 1.07 and $2.14 \%$, respectively $(p<0.05)$. At $7^{\text {th }}$ days of storage, the formation of TBARS in the emulsified sausages with 1.07 and $2.14 \%$ of FWGE decreased by 27.6 and $48.6 \%(p<0.05)$. 


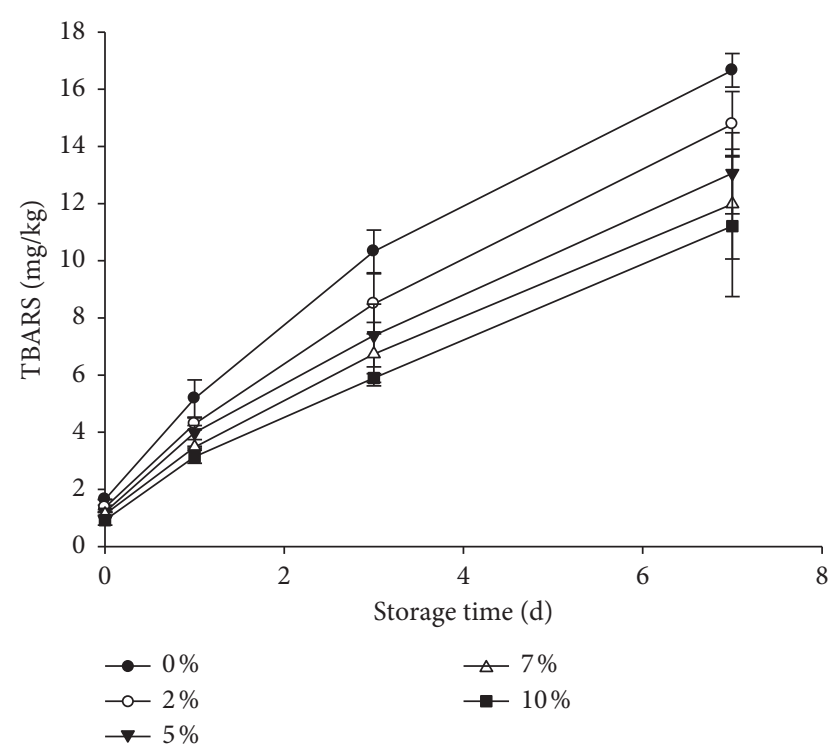

FIGURE 2: Oxidation stability of emulsified sausages with different ratios of fat replacement using FWGE during 7 days of storage at $4^{\circ} \mathrm{C}$.

Although increasing the FWGE content was able to retard the lipid oxidation in emulsified sausages, it leads to increase in cooking loss and hardness of emulsified sausages. When compared with the TBARS formed at 0 days of storage, it increased by $9.1,9.8,9.8,9.6$, and 11.1 times at 7 days of storage under the FWGE content of $0.43,1.07,1.50$, and $2.14 \%$, respectively $(p<0.05)$. It suggested that FWGE was prone to hinder the lipid oxidation at the early stage due to their $\mathrm{Fe}^{2+}$ chelating capacity and free radical scavenging capacity. Increasing the content of FWGE, the antioxidant properties of FWGE would enhance due to a higher content of antioxidant wheat germ protein hydrolysate and free polyphenols. They might show a higher $\mathrm{Fe}^{2+}$ chelating capacity and free radical scavenging capacity. This might result in diminishing the oxidation factors in the sausages. Our results suggested that coexistence of wheat germ protein hydrolysate and free polyphenols in FWGE might lead to synergic effect on antioxidant activities.

\section{Conclusions}

The antioxidant properties of defatted wheat germ were improved by fermentation with lactic acid bacteria (Lactobacillus plantarum DY-1). The enhancement in the antioxidant properties of fermented wheat germ extract (FWGE) might be due to the increase in their soluble protein content. The optimized fermentation conditions by terms of hydroxyl radical scavenging capacity were as follows: fermentation time of $26 \mathrm{~h}$, fermentation temperature of $35^{\circ} \mathrm{C}$, initial $\mathrm{pH}$ of 3.0 , solid to liquid ratio of $1 / 10$, and inoculum amount of $0.48 \mathrm{~g}$. The optimal hydroxyl radical scavenging capacity of FWGE was $72.8 \pm 2.9 \%$. FWGE was able to retard lipid oxidation of emulsified sausage. Replacing pork fat with 5\% FWGE resulted in better properties of emulsified sausage. The results suggested that biotransformation with lactic acid bacteria could be a promising way to enhance the bioactive properties of wheat germ. FWGE might have potential application in food industry. Further studies on isolation and purification of efficient antioxidants from FWGEs and the in vivo antioxidant activity tests are needed. And the enzymes involved in the fermentation of wheat germ on accumulation of the bioactive ingredients could be concerned.

\section{Data Availability}

The data used to support the findings of this study are included within the article.

\section{Conflicts of Interest}

The authors declare that there are no conflicts of interest.

\section{Acknowledgments}

This study was supported by the Jiangsu Province Ordinary University Graduate Research and Innovation Program (CXLX12_0672) and Natural Science Foundation of Jiangsu Province (BK20130494).

\section{References}

[1] W. Wang and K. Kannan, "Quantitative identification of and exposure to synthetic phenolic antioxidants, including butylated hydroxytoluene, in urine," Environment International, vol. 128, pp. 24-29, 2019, http://www.sciencedirect.com/ science/article/pii/S0160412019302922.

[2] Y. Kumar, D. N. Yadav, T. Ahmad, and K. Narsaiah, "Recent trends in the use of natural antioxidants for meat and meat products," Comprehensive Reviews in Food Science and Food Safety, vol. 14, no. 6, pp. 796-812, 2015, https://onlinelibrary. wiley.com/doi/10.1111/1541-4337.12156.

[3] J. Jiang and Y. L. Xiong, "Natural antioxidants as food and feed additives to promote health benefits and quality of meat products: a review," Meat Science, vol. 120, pp. 107-117, 2016, http://www. sciencedirect.com/science/article/pii/S0309174016300973.

[4] J. S. Ribeiro, M. J. M. C. Santos, L. K. R. Silva et al., "Natural antioxidants used in meat products: a brief review," Meat Science, vol. 148, pp. 181-188, 2019, http://www.sciencedirect. com/science/article/pii/S0309174018303577.

[5] Y. Peng, R. Gan, H. Li et al., "Absorption, metabolism, and bioactivity of vitexin: recent advances in understanding the efficacy of an important nutraceutical," Critical Reviews in Food Science and Nutrition, vol. 2020, pp. 1-16, 2020, https://www. tandfonline.com/doi/full/10.1080/10408398.2020.1753165.

[6] B. Xu, J. Yuan, L. Wang et al., "Effect of multi-frequency power ultrasound (MFPU) treatment on enzyme hydrolysis of casein," Ultrasonics Sonochemistry, vol. 63, p. 104930, 2020, http://www. sciencedirect.com/science/article/pii/S1350417719318437.

[7] S. Gupta and N. Abu-Ghannam, "Probiotic fermentation of plant based products: possibilities and opportunities," Critical Reviews in Food Science and Nutrition, vol. 52, no. 2, pp. 183-199, 2012, https://www.tandfonline.com/doi/full/10. 1080/10408398.2010.499779.

[8] F. Shahidi and P. Ambigaipalan, "Phenolics and polyphenolics in foods, beverages and spices: antioxidant activity and health effects-a review," Journal of Functional Foods, vol. 18, 
pp. 820-897, 2015, http://www.sciencedirect.com/science/ article/pii/S1756464615003023.

[9] K. Masisi, T. Beta, and M. H. Moghadasian, "Antioxidant properties of diverse cereal grains: a review on in vitro and in vivo studies," Food Chemistry, vol. 196, pp. 90-97, 2016, http:// www.sciencedirect.com/science/article/pii/S0308814615013643.

[10] B. A. Acosta-Estrada, J. A. Gutiérrez-Uribe, and S. O. SernaSaldívar, "Bound phenolics in foods, a review," Food Chemistry, vol. 152, pp. 46-55, 2014, http://www. sciencedirect.com/science/article/pii/S0308814613017305.

[11] F. Liu, Z. Chen, J. Shao, C. Wang, and C. Zhan, "Effect of fermentation on the peptide content, phenolics and antioxidant activity of defatted wheat germ," Food Bioscience, vol. 20, pp. 141-148, 2017, http://www.sciencedirect.com/ science/article/pii/S2212429217301268.

[12] A. K. Singh, J. Rehal, A. Kaur, and G. Jyot, "Enhancement of attributes of cereals by germination and fermentation: a review," Critical Reviews in Food Science and Nutrition, vol. 55, no. 11, pp. 1575-1589, 2015, https://www.tandfonline.com/ doi/full/10.1080/10408398.2012.706661.

[13] E. Arte, C. G. Rizzello, M. Verni, E. Nordlund, K. Katina, and R. Coda, "Impact of enzymatic and microbial bioprocessing on protein modification and nutritional properties of wheat bran," Journal of Agricultural and Food Chemistry, vol. 63, no. 39, pp. 8685-8693, 2015, https://pubs.acs.org/doi/abs/10. 1021/acs.jafc. 5b03495.

[14] Z. Karami, S. H. Peighambardoust, J. Hesari, B. AkbariAdergani, and D. Andreu, "Antioxidant, anticancer and ACEinhibitory activities of bioactive peptides from wheat germ protein hydrolysates," Food Bioscience, vol. 32, p. 100450, 2019, http://www.sciencedirect.com/science/article/pii/ S221242921830395X.

[15] K.-X. Zhu, C.-X. Lian, X.-N. Guo, W. Peng, and H.-M. Zhou, "Antioxidant activities and total phenolic contents of various extracts from defatted wheat germ," Food Chemistry, vol. 126, no. 3, pp. 1122-1126, 2011, http://www.sciencedirect.com/ science/article/pii/S0308814610015724.

[16] X. Zhang, Y. L. Xiong, J. Chen, and L. Zhou, "Synergy of licorice extract and pea protein hydrolysate for oxidative stability of soybean oil-in-water emulsions," Journal of $\mathrm{Ag}$ ricultural and Food Chemistry, vol. 62, no. 32, pp. 8204-8213, 2014, https://pubs.acs.org/doi/10.1021/jf5016126.

[17] L.-Y. Niu, S.-T. Jiang, and L.-J. Pan, "Preparation and evaluation of antioxidant activities of peptides obtained from defatted wheat germ by fermentation," Journal of Food Science and Technology, vol. 50, no. 1, pp. 53-61, 2013, https://link. springer.com/article/10.1007/s13197-011-0318-z.

[18] J. Song, J. Kim, and H. Jang, "Ferulic acid released by treatment with Aspergillus oryzae contributes to the cellular antioxidant capacity of wheat germ extract," Food Science and Biotechnology, vol. 23, no. 4, pp. 1327-1333, 2014, https://doi.org/10.1007/ s10068-014-0182-5https://ink.springer.com/article/10.1007/s100 68-014-0182-5.

[19] Y. Zhao, J. Zhang, Y. Wei, L. Ai, D. Ying, and X. Xiao, "Improvement of bread quality by adding wheat germ fermented with Lactobacillus plantarum dy-1," Journal of Food Quality, vol. 2020, p. 9348951, 2020, https://www.hindawi. com/journals/jfq/2020/9348951/.

[20] J. Zhang, X. Xiao, Y. Dong, J. Wu, F. Yao, and X. Zhou, "Effect of fermented wheat germ extract with Lactobacillus plantarum dy-1 on HT-29 cell proliferation and apoptosis," Journal of Agricultural and Food Chemistry, vol. 63, no. 9, pp. 24492457, 2015, https://doi.org/10.1021/acs.jafc.5b00041https:// pubs.acs.org/doi/10.1021/acs.jafc.5b00041.
[21] K. Fang, D. K. J. Lin, P. Winker, and Y. Zhang, "Uniform design: theory and application," Technometrics, vol. 42 , no. 3 , pp. 237-248, 2000, https://www.tandfonline.com/doi/abs/10. 1080/00401706.2000.10486045

[22] X. Tang, Z. He, Y. Dai, Y. L. Xiong, M. Xie, and J. Chen, "Peptide fractionation and free radical scavenging activity of zein hydrolysate," Journal of Agricultural and Food Chemistry, vol. 58, no. 1, pp. 587-593, 2010, https://pubs.acs.org/doi/10. $1021 /$ jf9028656.

[23] Y. Li, B. Jiang, T. Zhang, W. Mu, and J. Liu, "Antioxidant and free radical-scavenging activities of chickpea protein hydrolysate (CPH)," Food Chemistry, vol. 106, no. 2, pp. 444-450, 2008, http://www.sciencedirect.com/science/article/pii/ S0308814607004207.

[24] Y. Cheng, J. Chen, and Y. L. Xiong, "Chromatographic separation and tandem MS identification of active peptides in potato protein hydrolysate that inhibit autoxidation of soybean oil-in-water emulsions," Journal of Agricultural and Food Chemistry, vol. 58, no. 15, pp. 8825-8832, 2010, https:// pubs.acs.org/doi/10.1021/jf101556n.

[25] S. K. C. Chang, "Protein analysis," in Food Analysis, pp. 133-146, Springer, Berlin, Germany, 2010.

[26] J. N. BeMiller, "Carbohydrate analysis," in Food Analysis, pp. 147-177, Springer, Berlin, Germany, 2010.

[27] G. Nieto, M. Castillo, Y. L. Xiong, D. Álvarez, F. A. Payne, and M. D. Garrido, "Antioxidant and emulsifying properties of alcalase-hydrolyzed potato proteins in meat emulsions with different fat concentrations," Meat Science, vol. 83, no. 1, pp. 24-30, 2009, http://www.sciencedirect.com/science/ article/pii/S0309174009000813.

[28] Y. Cheng, P. O. Donkor, X. Ren et al., "Effect of ultrasound pretreatment with mono-frequency and simultaneous dual frequency on the mechanical properties and microstructure of whey protein emulsion gels," Food Hydrocolloids, vol. 89, pp. 434-442, 2019, http://www.sciencedirect.com/science/ article/pii/S0268005X18316527.

[29] Q. Tang and C. Zhang, "Data processing system (DPS) software with experimental design, statistical analysis and data mining developed for use in entomological research," Insect Science, vol. 20, no. 2, pp. 254-260, 2013, https://onlinelibrary.wiley. com/doi/abs/10.1111/j.1744-7917.2012.01519.x.

[30] M. G. Gänzle, "Enzymatic and bacterial conversions during sourdough fermentation," Food Microbiology, vol. 37, pp. 210, 2014, https://doi.org/10.1016/j.fm.2013.04.007http://www. sciencedirect.com/science/article/pii/S0740002013000762.

[31] S. J. Hur, S. Y. Lee, Y.-C. Kim, I. Choi, and G.-B. Kim, "Effect of fermentation on the antioxidant activity in plant-based foods," Food Chemistry, vol. 160, pp. 346-356, 2014, http://www. sciencedirect.com/science/article/pii/S0308814614005159.

[32] Y. Wang, J. Zhao, C. Liu, and W. Li, "Influence of $\gamma$-aminobutyric acid on gelling properties of heat-induced whey protein gels," Food Hydrocolloids, vol. 94, pp. 287-293, 2019, http://www. sciencedirect.com/science/article/pii/S0268005X19300220.

[33] Y. Wang, J. Zhao, W. Zhang, C. Liu, P. Jauregi, and M. Huang, "Modification of heat-induced whey protein gels by basic amino acids," Food Hydrocolloids, vol. 100, p. 105397, 2020, http://www. sciencedirect.com/science/article/pii/S0268005X19317977. 